\title{
Geociências
}

\section{Datação das formações Rio Claro e Piraçununga por termoluminescência}

\author{
(Thermoluminescence dating of Rio Claro and \\ Piraçununga Formations)
}

\author{
Sandra Regina Ferreira \\ Pós-Doutoranda - Programa Geociências \\ Área Geociências e Meio Ambiente UNESP - Campus de Rio Claro \\ E-mail:sfpizzolato@yahoo.com.br \\ Maria Rita Caetano Chang \\ Professora Titular - Departamento de Geologia Aplicada UNESP - Campus de Rio Claro \\ E-mail:mrchang@rc.unesp.br
}

\section{Resumo}

As formações Rio Claro e Piraçununga recobrem extensas áreas da Depressão Periférica Paulista, sobretudo na região das cidades homônimas, sobrepondo-se às formações Corumbataí e Pirambóia, em contato discordante. Caracterizam-se por fácies de areias finas a médias, localmente apresentando estratificações plano-paralelas e cruzadas e delgadas intercalações de lamas e cascalhos. As areias foram datadas pelo método de termoluminescência e apresentaram idade do Pleistoceno. A idade mais antiga, de 745.000 anos AP, foi determinada em amostras da formação Rio Claro; as demais apresentaram resultados entre 400.000 e 145.000 anos AP, para ambas unidades. A idade mais recente, de 15.000 anos AP, foi obtida em amostra de depósito coluvionar sobreposto à formação Piraçununga, próximo ao limite Pleistoceno/Holoceno.

Palavras-chave: Quaternário, método de termoluminescência, formações Rio Claro e Piraçununga.

\begin{abstract}
The Rio Claro and Piraçununga formations cover extensive areas of the Paulista Peripheral Depression, dominantly in the region of Rio Claro and Piraçununga cities. These units lie over the Corumbataí and Pirambóia formations, exhibiting discordant contacts. The Rio Claro and Piraçununga formations are composed of fine to medium sand facies, showing local cross-stratifications and parallel beddings with thin interbeddings of mud and gravel. These sands were dated by the Thermoluminescence Method, which indicated they were from the Pleistocene age. The oldest age $(745,000$ years BP) was found in deposits of the Rio Claro Formation; the other ages varied from 400,000 years BP to 145,000 years BP, for both formations. The youngest age (15,000 years BP - close to Pleistocene/ Holocene limit) was found in colluvial deposits, which rest on the Piraçununga Formation.
\end{abstract}

Keywords: Quaternary, thermoluminescence method, Rio Claro and Piraçununga Formations. 


\section{Introdução}

Esse estudo visa ao aprofundamento dos conhecimentos sobre as formações Rio Claro e Piraçununga, encontradas no centro-leste do Estado de São Paulo, com a finalidade de melhor compreender suas relações estratigráficas, particularmente quanto à cronologia de deposição dessas unidades.

Grande parte do conhecimento sobre essas formações foi adquirida nas décadas de 1960 e 1970, em trabalhos de cunho geológico e geomorfológico. A formação Rio Claro constitui um dos mais importantes registros sedimentares cenozóicos da Depressão Periférica Paulista, exibindo litificação em geral incipiente e espessura máxima de cerca de 30m.

Björnberg e Landim (1966) propuseram a designação litoestratigráfica formação Rio Claro para os sedimentos neocenozóicos situados entre 600 e $800 \mathrm{~m}$ de altitude, na região do município homônimo. Freitas et al. (1979) também descreveram as formações superficiais da Depressão Periférica Paulista e denominaram formação Piraçununga os sedimentos arenosos praticamente inconsolidados que ocorrem na região da cidade homônima.

Estudos mais recentes, como o de Melo (1995), evidenciam a complexidade e, especialmente, a dificuldade em se estabelecer uma cronologia dos eventos deposicionais e erosivos das unidades cenozóicas, de sorte que a determinação de suas idades, como as aqui apresentadas, pode auxiliar, não somente na elucidação desses eventos, mas, também, na correlação entre esses depósitos.

\section{Localização da área de estudo}

As formações Rio Claro e Piraçununga, admitidas como neocenozóicas pela maioria dos autores, estendem-se na região das cidades homônimas, localizadas no centro-leste do Estado de São Paulo. Aárea ora investigada compreende as folhas topográficas de Rio Claro e Piraçununga (IBGE, 1972a e b - 1:50.000), onde afloram sedimentos das duas unidades (Figura 1).

Inserida na Depressão Periférica Paulista (DPP), a área de estudo é caracterizada, sobretudo, por uma compartimentação em níveis aplainados, resultantes de ciclos erosivos, no sentido de Davis (1899, apud King, 1956), conforme admitido em diversos estudos (Björnberg \& Landim, 1966; Soares \& Landim, 1976; Penteado, 1976). Alguns setores apresentam relevo mais acidentado, em decorrência de intrusões de rochas básicas do magmatismo Serra Geral, encaixadas em unidades paleozóicas e mesozói- cas da bacia do Paraná, e de falhas ativas, principalmente no Mesozóico.

\section{Materiais e métodos}

Os sedimentos estudados foram amostrados em afloramentos das formações Rio Claro e Piraçununga, na área de estudo (Figura 1).

Na coleta de amostras para datações por termoluminescência, foram empregados tubos de PVC pretos, $\operatorname{com} 75 \mathrm{~cm}$ de comprimento e 2" de diâmetro, cravados, horizontalmente, nos níveis amostrados com auxílio de uma marreta, evi-

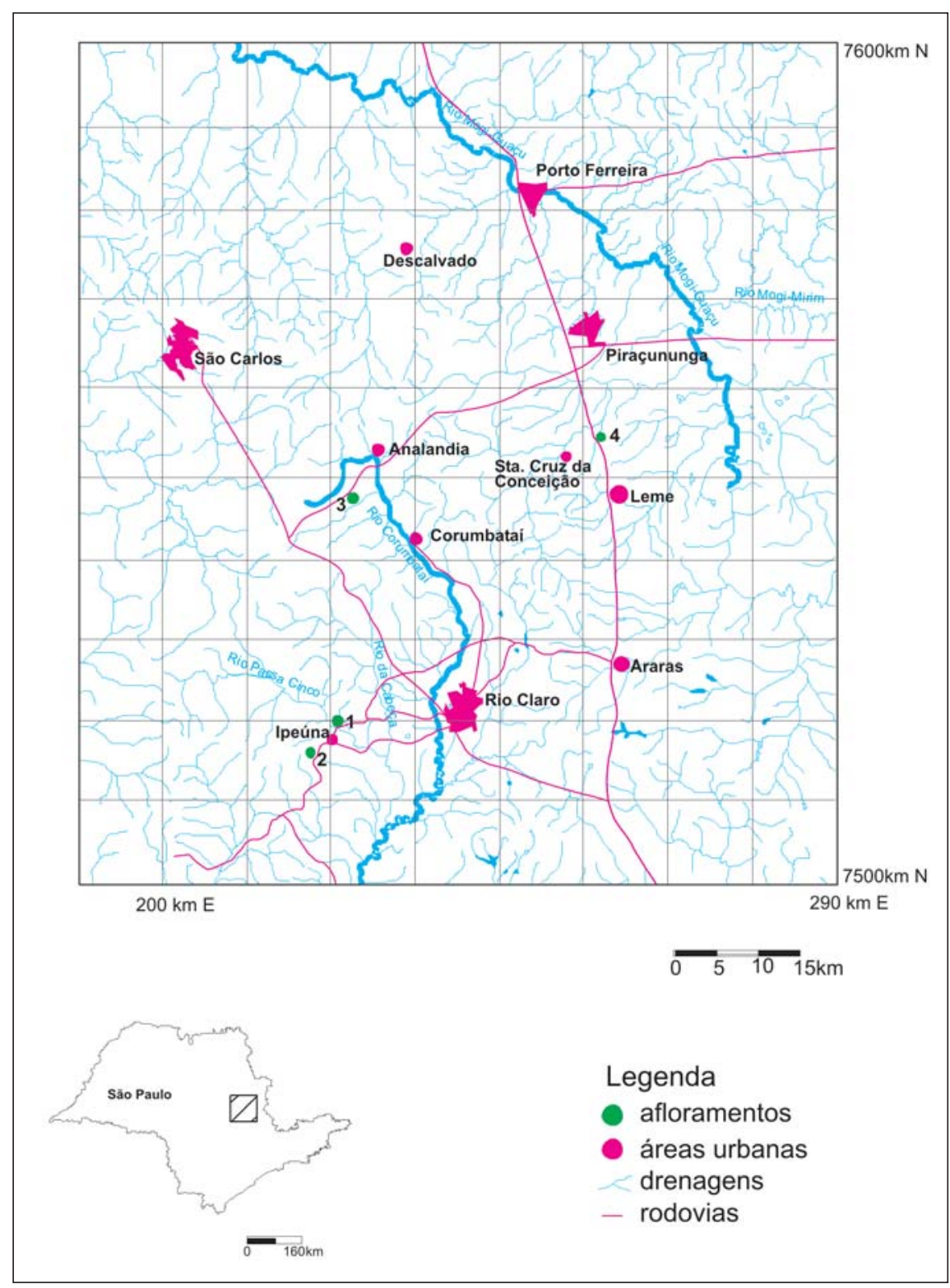

Figura 1 - Área de estudo com localização dos afloramentos estudados. 
tando-se exposição do material à radiação solar. Em câmara escura, as amostras foram retiradas dos tubos e acondicionadas em sacos plásticos pretos para envio ao laboratório para datação.

Foram coletadas 06 amostras para datação pelo Método da Termoluminescência, sendo 05 delas coletadas em sedimentos das formações Rio Claro e Piraçununga e 01 em cobertura coluvionar sobre a formação Piraçununga:

- Afloramento 01 (Figura 1, SP 191, próximo ao rio Passa Cinco; coordenadas UTM 7517.695mN e 222.992mE, altitude $601,1 \mathrm{~m}$ ) - uma amostra a $180 \mathrm{~cm}$ de profundidade - formação Rio Claro.

- Afloramento 02 (Figuras 1 e 2, SP 191, próximo ao trevo da cidade de Ipeúna; coordenadas UTM 7514.089mN e 219.915mE, altitude 609,7m) - duas amostras a 110 e $387 \mathrm{~cm}$ de profundidade - formação Rio Claro.

- Afloramento 03 (Figuras 1 e 3, SP 225, próximo à cidade de Analândia; coordenadas UTM $7560.148 \mathrm{mN}$ e $243.567 \mathrm{mE}$, altitude $653,4 \mathrm{~m}$ ) - duas amostras, sendo uma a $250 \mathrm{~cm}$ de profundidade, na formação Piraçununga, e outra a $150 \mathrm{~cm}$ de profundidade, em sedimento coluvionar.

- Afloramento 04 (Figura 1, SP 300, saída para Aguaí; coordenadas UTM $7575.734 \mathrm{mN}$ e $250.857 \mathrm{mE}$, altitude 593,3m) - uma amostra a 300 cm de profundidade - formação Piraçununga.

\subsection{Método de Termoluminescência}

A datação absoluta pelo método de termoluminescência (TL) constitui técnica que tem sido empregada com sucesso em sedimentos quaternários, principalmente aqueles submetidos a climas tropicais. Isto porque as altas temperatura e umidade, características desse tipo de clima, promovem a oxidação da matéria orgânica carbonosa, inviabilizando a utilização do método de datação por ${ }^{14} \mathrm{C}$. Proszynska-Bordas et al. (1992), estudan-

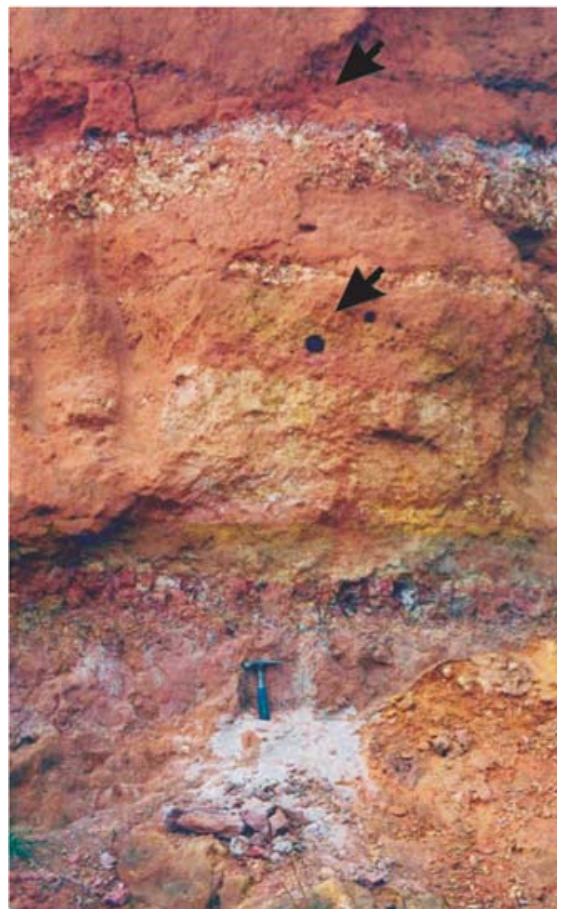

Figura 2 - Formação Rio Claro (SP 191 Afloramento 02). Setas indicam locais de amostragem.

do solos fósseis na região do Mediterrâneo, já atestavam a grande utilidade do método de TL em condições ambientais altamente oxidantes, uma vez que os estudos palinológicos são infrutíferos nessa situação.

A técnica de datação por termoluminescência baseia-se no princípio de que os cristais de quartzo, contidos em materiais arqueológicos e geológicos, aprisionam elétrons em armadilhas criadas pela exposição dos mesmos à radiação proveniente de raios cósmicos e de elementos radioativos do ambiente em que foram depositados; a TL é a luz emitida quando estes cristais são aquecidos por uma fonte de calor (Aitken, 1985; Watanabe \& Miyamoto, 1975).

Seis amostras - 3 da formação Rio Claro, 2 da formação Piraçununga e 1 de colúvio acima da formação Piraçununga - foram enviadas ao Laboratório de Vidros e Datação da FATEC (Faculdade de Tecnologia de São Paulo), onde foram preparadas para datação. A preparação das amostras envolveu: peneiramento com separação de grãos entre 88 e

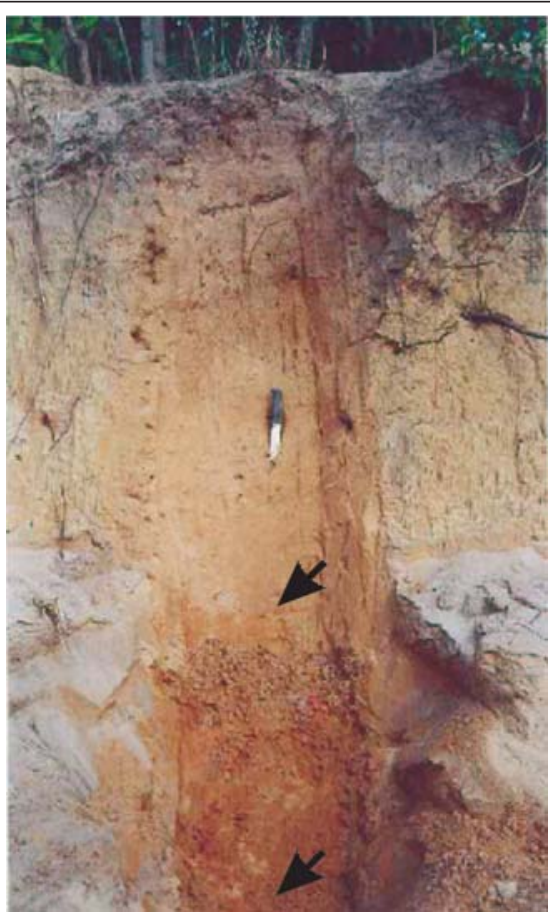

Figura 3 - Formação Piraçununga (abaixo da cascalheira) sobreposta por sedimento coluvionar (SP 225 - Afloramento 03). Setas indicam locais de amostragem.

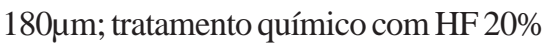
por 1 hora e com $\mathrm{HCl} 20 \%$ por 2 horas; e seleção dos grãos de quartzo pelo Método de Separação por Densidade, utilizando líquido de composição $3 \mathrm{Na}_{2} \mathrm{WO}_{4} \cdot 9 \mathrm{WO}_{3} \cdot \mathrm{H}_{2} \mathrm{O}$.

Para determinação das doses acumuladas, foi utilizado o Método de Regeneração Total, que consiste em exposição das amostras à luz solar durante 16 horas, divisão em diferentes porções e exposição à radiação $\gamma$ de ${ }^{60} \mathrm{Co}$. As amostras foram irradiadas e submetidas a tratamento térmico a $200^{\circ} \mathrm{C}$, durante $20 \mathrm{mi}$ nutos, para eliminação da parte instável do sinal de TL, que ocorre em baixas temperaturas, em laboratório do IPEN/CNEN (Instituto de Pesquisas Energéticas e Nucleares/Comissão Nacional de Energia Nuclear - SP).

As datações das amostras foram feitas na FATEC, utilizando o aparelho TL/OSL Automated Systems, Modelo 1100 série Daybreak Nuclear Instuments INC, com taxa de aquecimento de $10^{\circ} \mathrm{C} / \mathrm{s}$, filtro ótico Schott-BG-39 e atmosfera de $\mathrm{N}_{2}$ gasoso. Os valores das doses anuais 
foram calculados utilizando concentrações de ${ }^{40} \mathrm{~K},{ }^{232} \mathrm{Th}$, ${ }^{238} \mathrm{U}$ e ${ }^{235} \mathrm{U}$, medidas com detector de iodeto de sódio, e contribuição da radiação cósmica de $182 \mu \mathrm{Gy} /$ ano.

\section{Idade das formações Rio Claro e Piraçununga}

Desde os trabalhos pioneiros (Mezzalira, 1961/1962; Björnberg et al., 1964; Björnberg \& Landim, 1966; Fulfaro \& Suguio, 1968), a correlação entre as unidades cenozóicas da Depressão Periférica Paulista tem sido objeto de discussão. Dúvidas e controvérsias persistem, sobretudo pelas dificuldades impostas pela descontinuidade lateral dos depósitos e parcas evidências que permitam estabelecer suas relações estratigráficas.

Nesse contexto, as formações Rio Claro e Piraçununga têm sido consideradas genericamente, por diferentes autores, ora como cenozóicas, ora neocenozóicas ou ainda terciárias. A atribuição de idades mais precisas esbarra na inexistência de fósseis-guia, de forma que grande parte das idades consignadas às unidades está calcada em correlações com eventos de cunhos geomorfológico e/ou estrutural, que permitem apenas datação relativa.

Os primeiros relatos de fósseis são de Mezzalira (1961/1962), que descreveu restos vegetais de monocotiledôneas e folhas de plantas das ordens Myrtales, Ranales, Ebenales e Rutales. Björnberg et al. (1964) descreveram os depósitos cenozóicos da área do platô de Rio Claro e identificaram as famílias Nymphaeaceae, Potamogetonaceae e Alismataceae, semelhantes às formas atuais.

Penteado (1969) estudou a evolução do relevo da região e destacou o estabelecimento de superfície de aplainamento no Plioceno, que constituiria o assoalho primitivo de deposição da formação Rio Claro. Penteado (1976) considerou a reativação de antigas falhas, que, aliada a fatores climáticos, teria propici- ado condições para a deposição aluvial no Pleistoceno Inferior. Também AB'Saber (1969), entendendo que o assoalho da Depressão Periférica Paulista configuraria uma ampla superfície rasa e plana, embutida na superfície Neogênica (De Martonne, 1943), considerou que as formações Rio Claro e Piraçununga teriam se formado no Pleistoceno Inferior.

Fúlfaro e Suguio (1974), com base em correlações com eventos tectônicos e sedimentação continental, atribuíram idade miocênica à formação Rio Claro.

Soares e Landim (1976) consideraram que a sedimentação da formação Rio Claro teria ocorrido em rios meandrantes instalados em vale subseqüente ampliado, sem coalescência de planícies aluviais; posicionaram a unidade no limite Plioceno-Pleistoceno, com base em estimativa de taxa de rebaixamento erosivo.

Para Freitas et al. (1979), a Depressão Periférica Paulista teria sido formada por grabens e ampliada por erosão diferencial, de forma que as formações Rio Claro e Piraçununga constituiriam o entulhamento de fossas tectônicas, de idade terciária. Estudando a formação Piraçununga, definiram a Fácies Vargem Grande do Sul, composta por sedimentos argilosos de planície de inundação ou lagos, de suposta idade oligocênicamiocênica, e referiram-se ao restante da unidade, constituída de sedimentos mais grossos, arenosos, como Fácies Leme.

Duarte e Rezende-Martins (1985, in Melo 1995), estudando os fósseis de Vargem Grande do Sul, propuseram idade holocênica, devido à presença de famílias de vegetais ainda hoje viventes.

Zaine (1994) considerou a deposição da formação Rio Claro como o fecho deposicional do ciclo que elaborou a superfície Neogênica, admitindo que sua idade remontaria ao Mioceno.

Melo (1995) atribuiu idade terciária à formação Rio Claro, com base em fósseis de Magnoliopsedae. Identificou, ainda, vários outros depósitos mais jovens, sobrepostos às formações Rio Claro e Piraçununga, cujos fragmentos de carvão, datados por ${ }^{14} \mathrm{C}$, apresentaram idades compreendidas entre 6.500 e 8.500 anos AP.

Depreende-se, do anteriormente exposto, a fragilidade das idades atribuídas às formações Rio Claro e Piraçununga, não somente por tratarem-se de datações relativas, mas, principalmente, por não se basearem em dados plenamente confiáveis do ponto de vista cronológico. Dessa forma, o método de termoluminescência foi escolhido por oferecer a possibilidade de datação absoluta para essas unidades.

\section{Resultados}

Os resultados analíticos das amostras das formações Rio Claro e Piraçununga e de colúvio, quanto às doses anuais, doses acumuladas (P) e idades, são apresentados na Tabela 1 e Figura 4.

Os resultados obtidos posicionam os depósitos das formações Rio Claro e Piraçununga no Pleistoceno, uma vez que a idade mais antiga obtida foi de 745.000 anos AP (Afloramento 01 - formação Rio Claro) e as demais idades encontram-se entre 400.000 e 145.000 anos AP. O sedimento coluvionar data de 15.000 anos AP (Afloramento 03), situado, portanto, próximo ao limite Pleistoceno/Holoceno.

\section{Conclusões}

As formações Rio Claro e Piraçununga são constituídas por rochas arenosas e areno-cascalhosas, de depósitos de fundo de canal e de barras fluviais, com esparsos depósitos de planícies de inundação. Esses sedimentos foram depositados por rios entrelaçados, cujas capacidade e competência foram condicionadas por variações climáticas que promoveram fases de maior aporte de sedimentos, de obstrução de canais secundários e de alagamento de planícies aluviais (Ferreira, 2005). A sedimentação dessas formações ocorreu, aproximadamente, entre 150.000 e 800.000 anos AP, indicando contemporaneidade entre as unidades. Após período de erosão 
Sandra Regina Ferreira et al.

Tabela 1 - Resultados das datações por termoluminescência.

\begin{tabular}{c|c|c|c|c}
\hline Amostra & $\begin{array}{c}\text { Profundidade } \\
(\mathbf{c m})\end{array}$ & $\begin{array}{c}\text { Dose Anual } \\
(\boldsymbol{\mu} \text { Gy/ano) }\end{array}$ & $\begin{array}{c}\text { P } \\
(\mathbf{G y})\end{array}$ & $\begin{array}{c}\text { Idade } \\
(\mathbf{a n o s})\end{array}$ \\
\hline PFRC 01/01 & 180 & $340 \pm 2,0$ & 194,5 & $745.000 \pm 78.000$ \\
\hline PFRC 02/02 & 110 & $545 \pm 8,3$ & 168,1 & $305.000 \pm 35.000$ \\
\hline PFRC 02/01 & 387 & $800 \pm 14,8$ & 254,3 & $318.000 \pm 38.000$ \\
\hline PFPÇ 04/01 & 300 & $665 \pm 15$ & 91,2 & $145.000 \pm 18.000$ \\
\hline PFPÇ 03/01 & 250 & $445 \pm 2,6$ & 178,3 & $400.000 \pm 40.000$ \\
\hline Colúvio & 150 & $485 \pm 3,3$ & 7,67 & $15.000 \pm 1.600$ \\
\hline
\end{tabular}
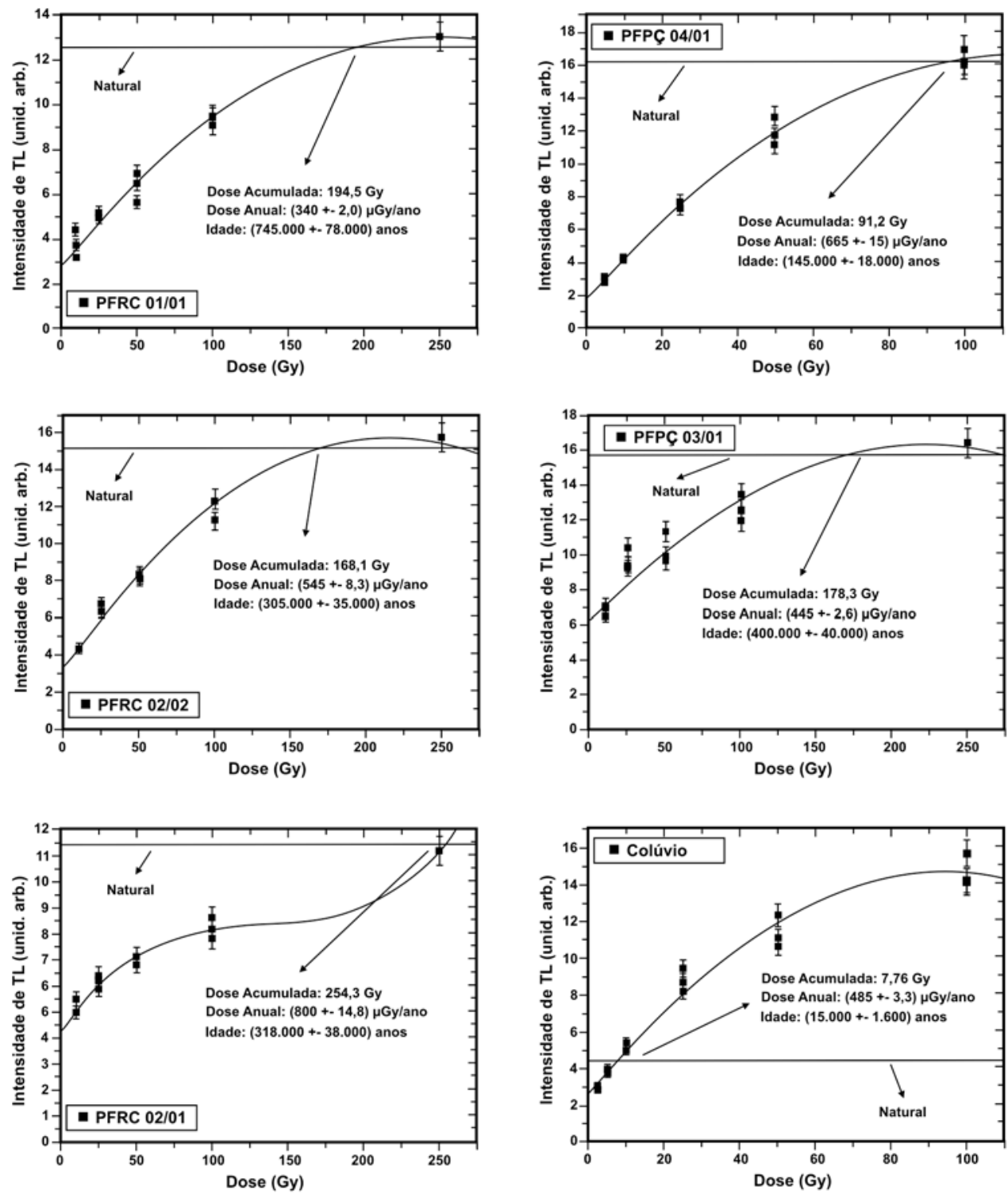

Figura 4 - Gráficos das datações por termoluminescência. 
que atingiu essas formações, provavelmente relacionada a eventos de instabilidade tectônica, depositou-se delgada camada coluvionar, na passagem do Pleistoceno ao Holoceno, recobrindo as unidades pleistocênicas.

A idade desses colúvios (15.000 anos AP) é concordante com as obtidas por Coutinho (1990), para depósitos superficiais na região de Piraçununga (8.600 anos AP), e por Gouveia et al. (2002), próximo à cidade de Anhembi (SP) (7.580 e 6.690 anos AP), com base em datação por ${ }^{14} \mathrm{C}$.

As idades obtidas por termoluminescência permitiram posicionar as formações Rio Claro e Piraçununga no Pleistoceno, com retrabalhamento coluvionar na passagem para o Holoceno. A idade pleistocênica, mais recente que as preconizadas pela maioria dos autores, dirime as incertezas intrínsecas ao material fóssil e mostra-se consistente com a evolução geológico-geomorfológica da área.

\section{Agradecimentos}

Os autores agradecem ao $\mathrm{CNPq}$, pela bolsa de doutoramento concedida à Dra. Sandra R. Ferreira, à FUNDUNESP (Fundação para o Desenvolvimento da UNESP), pelo apoio financeiro para trabalhos de campo, e ao LEBAC/UNESP, pelo apoio logístico.

\section{Referências bibliográficas}

AB'SABER, A. N. A. A Depressão Periférica Paulista: um setor das áreas de circundenudação pós-cretácica da bacia do Paraná. Boletim Instituto Geografia - USP. São Paulo, n. 15, p. 1-15, 1969.

AITKEN, M. J. Thermoluminescence dating. London: Academic Press, 1985.

BJÖRNBERG, A. J. S., LANDIM, P. M. B. Contribuição ao estudo da formação Rio Claro (Neocenozóico). Boletim Sociedade Brasileira de Geologia. São Paulo, v. 15, n. 4, p. 43-67, 1966.
BJÖRNBERG, A. J. S., LANDIM, P. M. B., MEIRELLES FILHO, G. M. Restos de plantas modernas em níveis elevados na região de Rio Claro (SP). Boletim Escola de Engenharia de São Carlos. São Carlos, v. 11, p. 3757, 1964.

COUTINHO, L. M. O cerrado e a ecologia do fogo. Ciência Hoje, São Paulo, v. 12, n. 68, p. 22-30, 1990.

DE MARTONNE, E. Problemas morfológicos do Brasil tropical atlântico. Revista Brasileira de Geografia, v. 5, n.4, p. 523-550, 1943.

FERREIRA, S. R. Análise pedoestratigráfica das formações Rio Claro e Piraçununga, no centro-leste do Estado de São Paulo. Rio Claro: Instituto de Geociências e Ciências Exatas, Universidade Estadual Paulista, 2005. 157f. (Tese de Doutorado).

FREITAS, R. O., MEZZALIRA, S., ODA, G. H., VIEIRA, P. C., TORRES, C. C., HACHIRO, J., TOMINAGA, L. K., DEHIRA, L., MASSOLI, M., AZEVEDO, A. A. B., PRESSINOTI, M. M. N. Projeto levantamento geológico de formações superficiais. In: SIMPÓSIO REGIONAL DE GEOLOGIA, 2. Atas... Rio Claro: SBG, 1979. v. 2. p. 263-277. 1979.

FÚLFARO, V. J., SUGUIO, K. A formação Rio Claro (Neocenozóico) e seu ambiente de deposição. Revista do Instituto Geográfico e Geológico. São Paulo, v. 20, p. 45-60. 1968.

FÚlfARO, V. J., SUGUIO, K. O Cenozóico paulista: gênese e idade. In: CONGRESSO BRASILEIRO DE GEOLOGIA, 28. Anais... Porto Alegre: SBG, v. 3. p. 91-101, 1974.

GOUVEIA, S. E. M., PESSENDA, L. C. R., ARAVENA, R., BOULET, R., SCHELL-YBERT, R., BENDASSOLI, J. A., RIBEIRO, A. S., FREITAS, H. A. Carbon isotopes in charcoal and soils in studies of paleovegetation and climate changes during the late Pleistocene and the Holocene in the southeast and centerwest regions of Brazil. Global Planetary Change, n. 33, p. 95-106, 2002.

IBGE - INSTITUTO BRASILEIRO DE GEOGRAFIA E ESTATÍSTICA. Folha topográfica Piraçununga. SF-23-V-C-V-3. Rio de Janeiro, 1972 a. Escala 1:50.000.
IBGE - INSTITUTO BRASILEIRO DE GEOGRAFIA E ESTATÍSTICA. Folha topográfica Rio Claro. SF23-Y-A-I-4. Rio de Janeiro, 1972 b. Escala 1:50.000.

KING, L. C. A geomorfologia do Brasil oriental. Revista Brasileira de Geografia. Rio de Janeiro, ano XVIII, n. 2, p. 3-265, abril-junho, 1956.

MELO, M. S. de. A formação Rio Claro e depósitos associados: sedimentação neocenozóica na Depressão Periférica Paulista. São Paulo: Instituto de Geociências, Universidade de São Paulo, 1995. 144f. (Tese de Doutorado).

MEZZALIRA, S. Novas ocorrências de vegetais fósseis cenozóicos no Estado de São Paulo. Revista do Instituto Geográfico e Geológico. São Paulo, v.15, p. 73-94, 1961/1962.

PENTEADO, M. M. A Bacia de Sedimentação de Rio Claro - Estado de São Paulo. Geographica - Revista da Sociedade de Geografia de Lisboa. Lisboa, v. 5, n. 17, p. 38-61, 1969.

PENTEADO, M. M. Geomorfologia do Setor Centro-Ocidental da Depressão Periférica Paulista. São Paulo: USP - Instituto de Geografia, 1976. (Série Teses e Monografia n. 22).

PRÓSZYNSKA-BORDAS, H., STANSKA-PRÓSZYNSKA, W., PRÓSZYNKI, M. TL dating of river terrace with fossil soils in the Mediterranean region. Quaternary Science Reviews, v. 11, p. 53-60. 1992.

SOARES, P. C., LANDIM, P. M. B. Depósitos cenozóicos na região centro-sul do Brasil. Notícia Geomorfológica. Campinas, v. 16, n. 31, p. 17-39, 1976.

WATANABE, S., MIYAMOTO, M. Datação de peças arqueológicas pelo Método de Termoluninescência. Anais Academia Brasileira de Ciências. Rio de Janeiro, v. 47, n. 2, p. 197-213, 1975.

ZAINE, J. E. Geologia da formação Rio Claro na folha de Rio Claro (SP). Rio Claro: Instituto de Geociências e Ciências Exatas, Universidade Estadual Paulista, 1994. 90f. (Dissertação de Mestrado).

Artigo recebido em 10/07/2007 e aprovado em 14/12/2007. 